UDC 519.6

DOI: $10.22363 / 2658-4670-2020-28-4-398-405$

\title{
Numerical modeling of laser ablation of materials
}

\author{
Ilkizar V. Amirkhanov, Nil R. Sarker, Ibrohim Sarkhadov \\ Laboratory of Information Technology \\ Joint Institute for Nuclear Research \\ 6, Joliot-Curie St., Dubna, Moscow region, 141980, Russian Federation
}

(received: November 10, 2020; accepted: November 12, 2020)

In this paper, we report a numerical simulation of laser ablation of a material by ultrashort laser pulses. The thermal mechanism of laser ablation is described in terms of a one-dimensional nonstationary heat conduction equation in a coordinate system associated with a moving evaporation front. The laser action is taken into account through the functions of the source in the thermal conductivity equation that determine the coordinate and time dependence of the laser source. For a given dose of irradiation of the sample, the profiles of the sample temperature at different times, the dynamics of the displacement of the sample boundary due to evaporation, the velocity of this boundary, and the temperature of the sample at the moving boundary are obtained. The dependence of the maximum temperature on the sample surface and the thickness of the ablation layer on the radiation dose of the incident laser pulse is obtained.

Numerical calculations were performed using the finite difference method. The obtained results agree with the results of other works obtained by their authors.

Key words and phrases: Numerical simulation, ablation, pulsed lasers, heat conduction equation

\section{Introduction}

In recent years, pulsed laser ablation [1]-[3] (any process of laser-stimulated removal of matter, including the emission of electrons) of various materials has attracted more and more interest from the point of view of fundamental study of processes in matter under extreme conditions of ultrafast energy supply. This implies constructing a new physical theory describing strongly nonlinear effects.

For a detailed analysis of the processes in the experiment, it is required to measure various characteristics of the ablation processes with pico- and femtosecond time resolution, which in itself is a rather difficult task. Therefore, the problem of mathematical modeling of physical phenomena in this area becomes extremely urgent.

To describe the dynamics of fast processes in a substance, the method of molecular dynamics (MD) can be used [4]. MD is quite effective for

(C) Amirkhanov I. V., Sarker N.R., Sarkhadov I., 2020

This work is licensed under a Creative Commons Attribution 4.0 International License http://creativecommons .org/licenses/by/4.0/ 
microscopic analysis of the mechanisms of melting and evaporation under overheating conditions both in the bulk of the target [5] and for a system with a free surface [6]. The emergence and propagation of pressure waves generated by laser radiation [7], [8], as well as the dynamics of laser ablation [9], is well modeled using MD.

In this paper, we consider continuous methods (various modifications of the heat equation) for modeling the effect of laser radiation on matter.

The evaporation process is mathematically described within the framework of the boundary value problem of thermal conductivity for a condensed medium in a coordinate system associated with a moving solid-vapor interface or a melt-vapor interface on which evaporation occurs. If we do not take into account the lateral removal of the laser radiation energy due to thermal conductivity, which is valid under the strict condition $r_{0} \gg \sqrt{a_{T} \tau}$, where $\tau$ is the duration of the laser beam exposure to the material, $a_{T}$ is the thermal conductivity, $r_{0}$ is the radius of the overheating spot, then the problem of the motion of the evaporation boundary can be considered within the framework of the one-dimensional model [3]. In Ref. [10], the primary results of numerical simulation of ablation of materials were published. In this paper, the required work is presented in a more extended form.

\section{Setting of the problem}

Numerical modeling of laser ablation of materials was carried out based on the heat conduction equation written in a moving coordinate system associated with the evaporation front, with initial and boundary conditions [2]:

$$
\begin{gathered}
\rho(T) c(T)\left[\frac{\partial T}{\partial t}-v\left(T_{s}\right) \frac{\partial T}{\partial z}\right]=\frac{\partial}{\partial z}\left(\lambda(T) \frac{\partial T}{\partial z}\right)+A(z, t), \quad 0<z<z_{\max } \\
T(z, 0)=T_{0} ; \quad 0 \leqslant z \leqslant z_{\max } \\
\left.\lambda(T) \frac{\partial T(z, t)}{\partial z}\right|_{z=0} ^{t}=v\left(T_{s}\right) L_{e v} \rho \\
T\left(z_{\max }, t\right)=T_{0} ; \quad h=\int_{0}^{t} v(t) d t, \quad T_{s}=T(0, t)
\end{gathered}
$$

where $c(T), \lambda(T), \rho(T)$ are the specific heat, thermal conductivity and density of the material at the temperature $T(z, t), h(t)$, respectively is the depth of the crater on the surface of the sample at time $t, z_{m}$ is the maximum distance, $v\left(T_{s}\right)$ is the velocity of the boundary displacement due to evaporation, $L_{e v}$ is the specific heat of sublimation. The source function $A(z, t)$ has the form [2]

$$
\begin{gathered}
A(z, t)=f_{1}(z) f_{2}(t), \\
f_{1}(z)=A_{s} \alpha e^{-\alpha z} e^{-\alpha_{g} h}, \quad A_{s}=1-R\left(T_{s}\right), \quad f_{2}(t)=I_{0} f(t) .
\end{gathered}
$$

Here $I_{0}$ is the laser intensity, $R\left(T_{s}\right)$ is the reflection coefficient of the laser from the sample surface, $\alpha, \alpha_{g}$ are the absorption coefficients of the laser 
pulse in the sample material and in the vapor, respectively. The irradiation dose $\Phi$, the intensity of the source $I_{0}$ and the temporal form of the source $f(t)$ are related by the relation:

$$
\Phi=I_{0} \int_{0}^{\infty} f(t) d t
$$

Here the source function has a factorized form, as in the work [11], when the material is affected by a pulsed beam of charged particles rather than by a laser pulse. In general, the heat capacity, thermal conductivity, and density of the material depend on temperature. In a particular case, the dependence of some parameters of the sample material can be neglected. In this work, the temperature dependence of the density of the sample material and the laser reflection coefficient is neglected.

\section{Discussion of numerical results}

In Ref. [2], problem (1)-(4) was solved by the method of moments for a polyimide material. In our work, this problem was solved using the finite difference explicit scheme [12]. The temporal shape of the source $f(t)$, the temperature dependence of the boundary motion velocity due to evaporation $v_{s}(T)$, the specific heat $c(T)$ and the thermal conductivity $\lambda(T)$ are taken for the polyimide material similar as in Ref. [2]:

$f(t)=\frac{t}{t_{1}} \exp \left\{-\frac{t}{t_{1}}\right\} ; t_{1}=6.13 n s, c(T)=2550-1590 \cdot \exp \left\{\frac{300-T}{460}\right\} \frac{\mathrm{J}}{\mathrm{kgK}}$,

$\lambda(T)=0.155 \cdot\left(\frac{T}{300}\right)^{0.28} \frac{W}{m K}, v=v_{0} e^{-T_{a} / T_{s}}, v_{0}=3 \cdot 10^{4} \mathrm{~m} / \mathrm{s} ; T_{a}=15700 \mathrm{~K}$.

Figure 1 shows plots of these dependencies.

Figure 2 shows the temperature profiles of a polyimide sample at different times: $t_{j}=j \cdot 5 \mathrm{~ns} ; j=1.10$, the dynamics of the sample boundary motion due to evaporation, the velocity of this boundary motion, and the sample temperature at the moving boundary $x=h(t)$, when exposed to energy fluence $\Phi=10^{3} \mathrm{~J} / \mathrm{m}^{2}$ with parameters $A_{s}=0.93, \alpha=4.25 \cdot 10^{7} \mathrm{~m}^{-1}\left(\alpha_{g}=0.45 \alpha\right)$, $L_{e v}=5 \cdot 10^{5} \mathrm{~J} / \mathrm{kg}, \rho=1420 \mathrm{~kg} / \mathrm{m}^{3}$.

Figure 3 shows the dependencies of the maximal temperature at the sample surface $T_{\text {max }}(h(t), t)$ and the crater depth $h(t)$ on the radiation dose $\Phi$ for four sets of values of parameters $A_{s}$ and $\alpha$ :

1) $A_{s}=0.93, \alpha=4.25 \cdot 10^{7} \mathrm{~m}^{-1}$;

2) $A_{s}=0.88, \alpha=3.1 \cdot 10^{7} \mathrm{~m}^{-1}$;

3) $A_{s}=0.89, \alpha=10^{7} \mathrm{~m}^{-1}$;

4) $A_{s}=0.9, \alpha=0.32 \cdot 10^{7} \mathrm{~m}^{-1}$.

The source intensity $I_{0}$ in this case varies from $3 \cdot 10^{6} \mathrm{~W} / \mathrm{cm}^{2}$ to 3 . $10^{7} \mathrm{~W} / \mathrm{cm}^{2}$. The obtained results agree with those of Ref. [2]. 

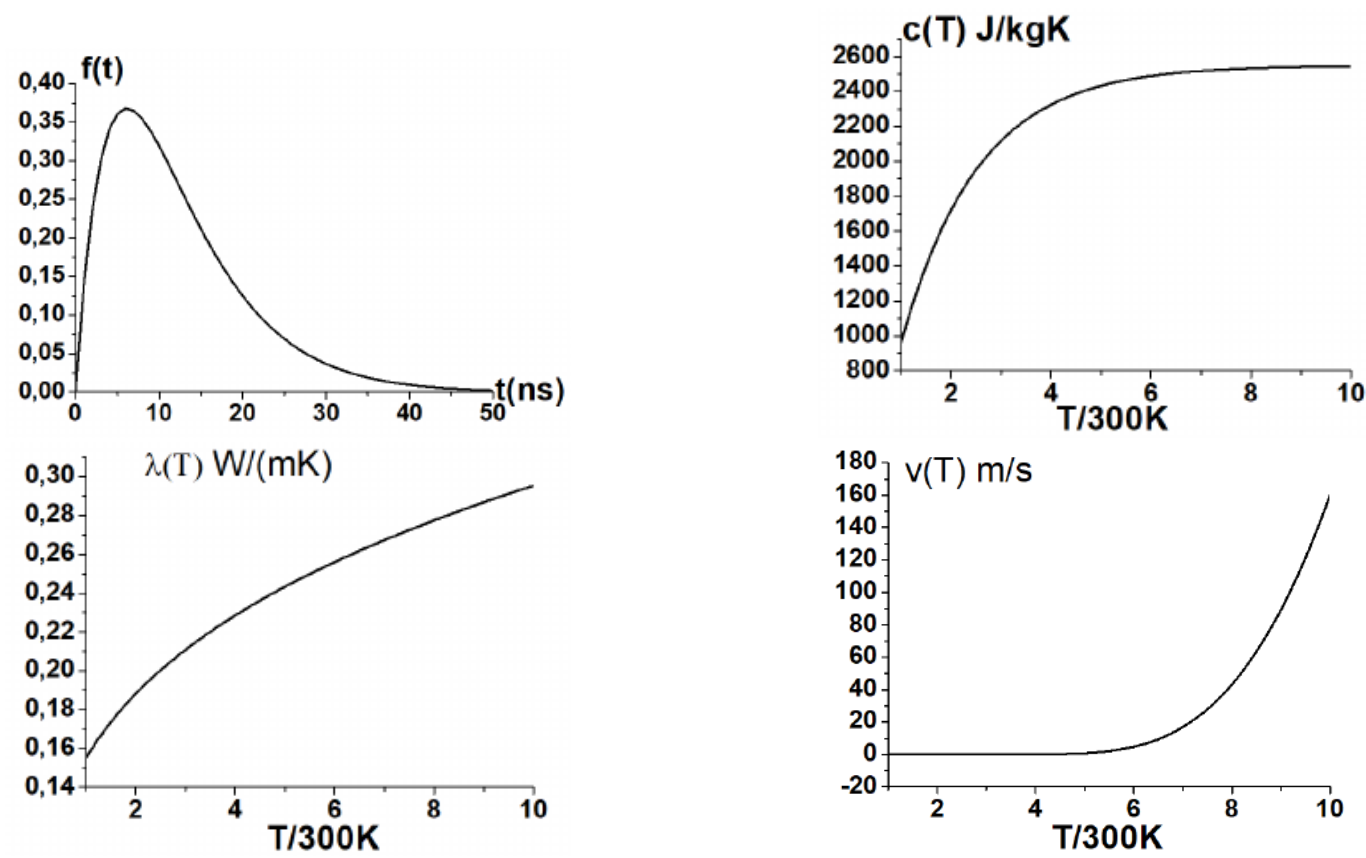

Figure 1. Source temporal shape $f(t)$, temperature dependence of specific heat $c(T)$, thermal conductivity $\lambda(T)$ and boundary motion velocity $v(T)$ due to evaporation
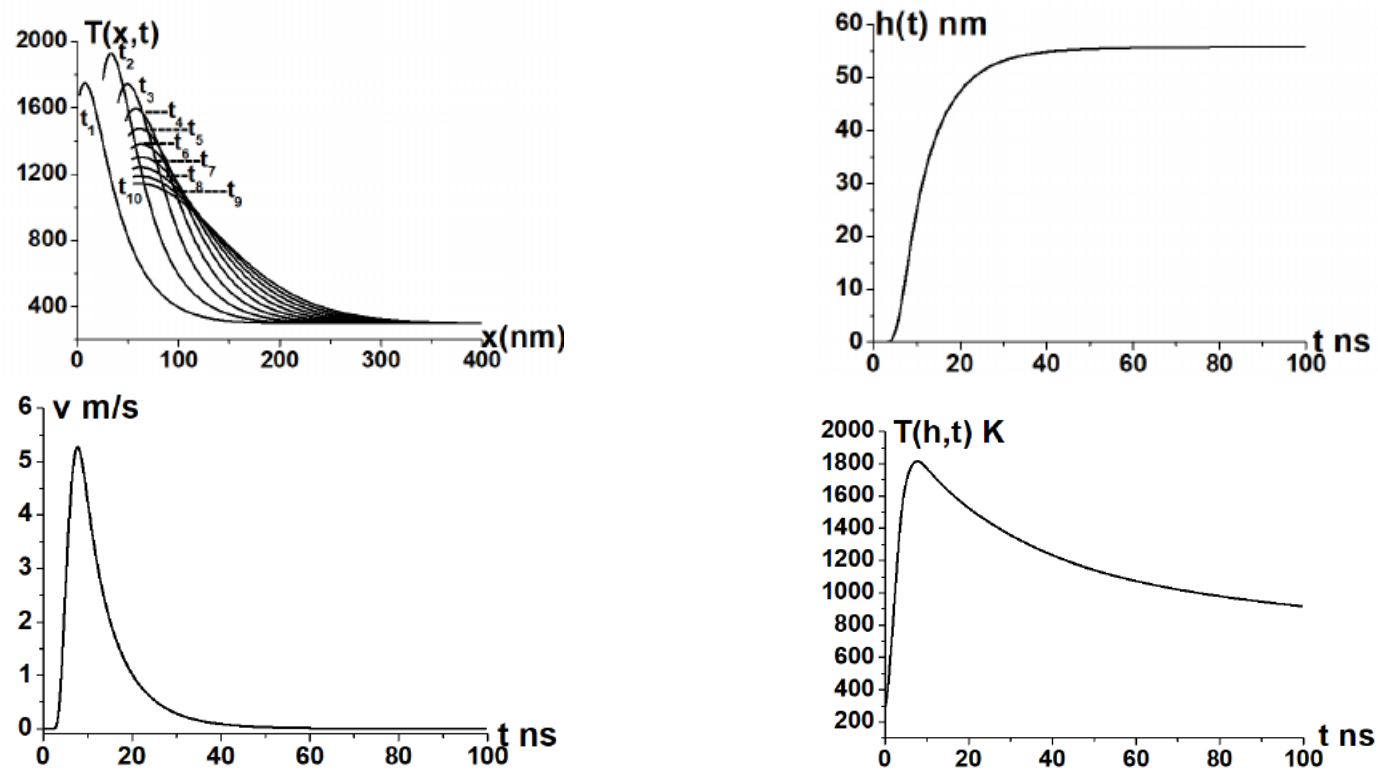

Figure 2. Temperature profiles of polyimide sample at different times:

$t_{j}=j \cdot 5 n s ; j=1,10$, dynamics of sample boundary motion due to evaporation, velocity of this boundary and the sample temperature at the moving boundary $x=h(t)$ under the exposure to energy fluence $\Phi=10^{3} \mathrm{~J} / \mathrm{m}^{2}$ 

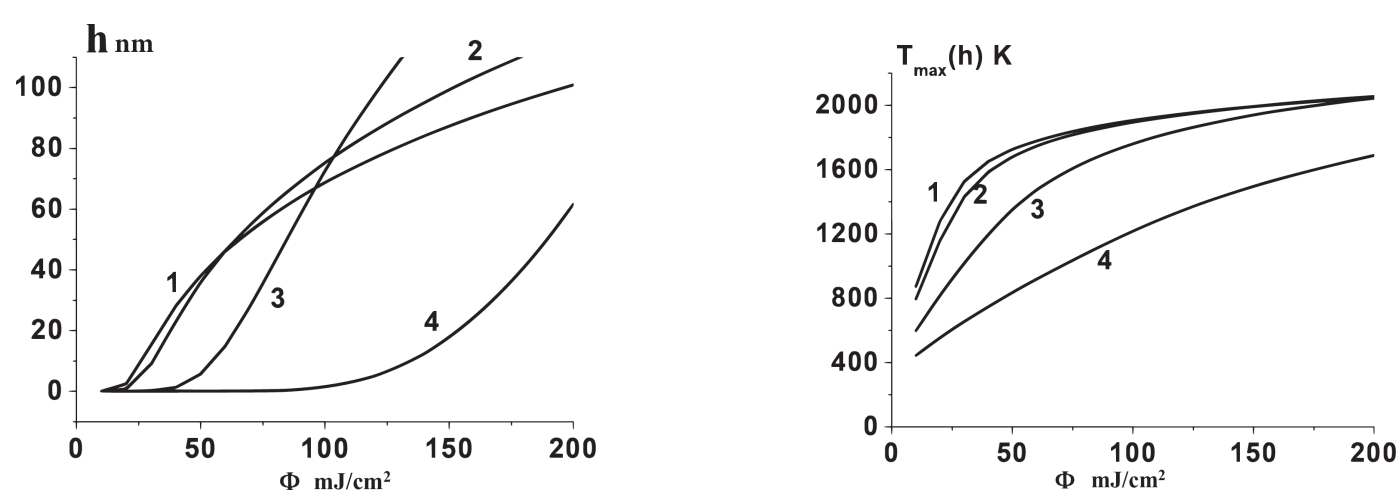

Figure 3. Dependencies of the maximal temperature at the sample surface $T_{\max }(h(t), t)$ and the crater depth $h(t)$ on the irradiation doze $\Phi$ for four sets of values for $A_{s}, \alpha$

\section{Conclusion}

For a given dose of the sample irradiation, the profiles of the sample temperature at different times, the dynamics of the displacement of the sample boundary due to evaporation, the velocity of this boundary and the temperature of the sample at the moving boundary were obtained. The dependencies of the temperature maximum on the sample surface and the thickness of the ablation layer on the radiation dose of the incident laser pulse are determined.

Numerical calculations were performed using the finite difference method. The obtained results agree with the results of works of other authors. When using shorter laser pulses in the ablation kinetics, arised features that can no longer be described within the framework of the conventional thermal model. In this case, studies are carried out within the framework of other models (two-temperature model, hydrodynamic model, etc.), which is the subject of further research.

\section{Acknowledgments}

The work was carried out by financial support of Russian Foundation for Basic Research No. 19-01-00645a and No. 20-51-44001 mong-a.

\section{References}

[1] L. A. Zakharov and N. M. Bulgakov, "Numerical simulation of laser ablation of metals and polymers when exposed to pulses of infrared radiation: the effect of the initial temperature of the sample [Chislennoe modelirovanie lazernoj ablyacii metallov i polimerov pri vozdejstvii impul'sami infrakrasnogo izlucheniya: vliyanie nachal'noj temperatury obrazca]," Vestnik NGU. Seriya: Fizika, vol. 5, no. 1, pp. 39-47, 2010, in Russian.

[2] S. I. Anisimov and B. S. Lukyanchuk, "Selected problems of laser ablation theory," Phys. Usp., no. 45, pp. 293-324, 2002. DOI: 10.1070/ PU2002v045n03ABEH000966. 
[3] V. P. Veiko, M. N. Libenson, G. G. Chervyakov, and E. B. Yakovlev, Interaction of Laser Radiation with Matter. Power Optics /Vzaimodeistvie lazernogo izlucheniya s veshchestvom. Silovaya optika]. Moscow: Fizmatlit, 2008, in Russian.

[4] M. P. Allen and D. J. Tildesley, Computer Simulation of Liquids. Walton Street, Oxford OX2 6DP: Clarendon Press, 1991.

[5] Z. H. Jin, P. Gumbsch, K. Lu, and E. Ma, "Melting mechanisms at the limit of superheating," Physical Review Letters, vol. 87, no. 5, p. 055703 , Jul. 2001. DOI: 10.1103/PhysRevLett.87.055703.

[6] F. F. Abraham and J. Q. Broughton, "Pulsed melting of silicon (111) and (100) surfaces simulated by molecular dynamics," Physical Review Letters, vol. 56, no. 7, pp. 734-737, 1986. DOI: 10.1103/PhysRevLett. 56.734.

[7] L. V. Zhigilei and B. J. Garrison, "Pressure waves in microscopic simulations of laser ablation," Materials Research Society Symposium Proceedings, vol. 538, pp. 491-496, 1999.

[8] J. I. Etcheverry and M. Mesaros, "Molecular dynamics simulation of the production of acoustic waves by pulsed laser irradiation," Physical Review B, vol. 60, no. 13, pp. 9430-9434, 1999. DOI: 10.1103/PhysRevB . 60.9430 .

[9] L. V. Zhigilei and B. J. Garrison, "Microscopic mechanisms of laser ablation of organic solids in the thermal and stress confinement irradiation regimes," Journal of Applied Physics, vol. 88, no. 3, pp. 1281-1298, 2000. DOI: $10.1063 / 1.373816$.

[10] I. V. Amirkhanov, N. R. Sarker, and I. Sarkhadov, "Numerical simulation of laser ablation of materials," in Proceedings of the 10th International Conference "Information and Telecommunication Technologies and Mathematical Modeling of High-Tech Systems" (ITTMM-2020), Moscow, in Russian, 2020, pp. 237-239.

[11] I. V. Amirkhanov, E. V. Zemlyanaya, I. V. Puzynin, T. P. Puzynina, and I. Sarhadov, On the influence of the source shape in the model of phase transitions in metals irradiated with pulsed ion beams /O vliyanii formy istochnika $v$ modeli fazovyh perekhodov $v$ metallah, obluchaemyh impul'snymi puchkami ionov]. Dubna: JINR Communication P11-200278, 2002, p. 18, in Russian.

[12] A. A. Samarskiy, The theory of difference schemes [Teoriya raznostnyh skhem], Russian. Moscow: Nauka, 1983, pp. 258-276, in Russian.

\section{For citation:}

I. V. Amirkhanov, N. R. Sarker, I. Sarkhadov, Numerical modeling of laser ablation of materials, Discrete and Continuous Models and Applied Computational Science 28 (4) (2020) 398-405. DOI: 10.22363/2658-4670-2020-28-4-398-405.

\section{Information about the authors:}

Amirkhanov, Ilkizar V. - Candidate of Physical and Mathematical Sciences, Head of Sector "Scientific Division of Computational Physics". Laboratory of Information Technologies of the Joint Institute for Nuclear Research 
(e-mail: camir@jinr.ru, ORCID: https://orcid.org/0000-0003-2621-144X, Scopus Author ID: 6507929197)

Sarker, Nil R. - Candidate of Physical and Mathematical Sciences, Senior Researcher "Scientific Division of Computational Physics". Laboratory of Information Technologies of the Joint Institute for Nuclear Research (e-mail: sarker@jinr.ru, ORCID: https://orcid.org/0000-0003-0690-2534, Scopus Author ID: 14829498100)

Sarkhadov, Ibrohim - Candidate of Physical and Mathematical Sciences, Senior Researcher "Scientific Division of Computational Physics". Laboratory of Information Technologies of the Joint Institute for Nuclear Research (e-mail: ibrohim@jinr.ru, ORCID: https://orcid.org/0000-0001-5534-3332, Scopus Author ID: 14829718300) 
УДК 519.6

DOI: $10.22363 / 2658-4670-2020-28-4-398-405$

\title{
Численное моделирование лазерной абляции материалов
}

\author{
И. В. Амирханов, Н. Р. Саркер, И. Сархадов \\ Лаборатория информационных технологий \\ Обгединённый институт ядерных исследований \\ ул. Жолио-Кюри, д. 6, Дубна, Московская область, 141980, Россия
}

В работе проведено численное моделирование лазерной абляции материала под действием ультракоротких лазерных импульсов. Тепловой механизм лазерной абляции описывается в рамках одномерного нестационарного уравнения теплопроводности в системе координат, связанной с движущимся фронтом испарения. Действие лазера учитывается через функции источника в уравнении теплопроводности, задавая координатную и временную зависимости источника лазера. Для заданной дозы облучения образца получены профили температуры образца при разных временах, динамике перемещения границы образца из-за испарения, скорости перемещения этой границы и температуры образца на движущейся границе. Получены зависимость максимума температуры на поверхности образца и толщины слоя абляции от дозы излучения падающего лазерного импульса.

Численные расчеты проведены с применением метода конечных разностей. Полученные результаты согласуются с результатами работ других исследователей.

Ключевые слова: численное моделирование, абляция, импульсные лазеры, уравнение теплопроводности 